\title{
Ethnocultutal identity of the indigenous people of the Arctic (a case study of Anabar district in Yakutia)
}

\author{
Viktoriya Filippova ${ }^{1, *}$, Liliya Vinokurova $^{1}$, Yana Sannikova ${ }^{1}$, Natalya Zakharova ${ }^{1}$, and Akulina Mestnikova ${ }^{2}$ \\ ${ }^{1}$ Institute for Humanities Research and Indigenous Studies of the North, Siberian branch, Russian Academy of Sciences, \#1 \\ Petrovskogo str., Yakutsk, 677027, Russia \\ ${ }^{2}$ Federal State Budget Educational Institution of Higher Education "Churapcha state institute of physical education and sports", \\ \#2a Sportivnaya str., Churapcha, 678670, Russia
}

\begin{abstract}
The article presents the preliminary results of a comprehensive study on the social anthropology of the cultural landscape of the Khatango-Anabar region as an integral historical and cultural space, formed as a result of the interaction of man and nature, local ethnic communities and social institutions. The purpose of the article is to study the regional ethno-cultural identification of the population living in one of the Arctic regions of Yakutia - Anabar. The field research, including interviews, a sociological survey, and a psycholinguistic experiment revealed indicators for determining the ethnocultural identity. Three main criteria of ethnocultural identity of residents of Anabar district were identified. These are territorial, cultural and linguistic ones. It was found that the unifying indicator of the population living in this area is regional identity as Anabarians.
\end{abstract}

\section{Introduction}

The ethnocultural diversity of the Russian population is studied within various social humanitarian disciplines. Despite a significant number of Russian and foreign publications, most of the works are aimed at studying Russian identity; issues of regional and local identity remain outside the scope of research [1].

The relevance of this article is due to the insufficient study of regional ethnocultural self-identification. Assuming that ethnocultural identity is based on language, culture, historical past, the research supported by the RFBR (project 20-09-00257A) was conducted to study indigenous peoples of the Arctic living in Anabar national (Dolgan-Evenk) ulus (district) of the Republic of Sakha (Yakutia).

The choice of the region was determined by the Arctic natural landscapes and ethnic composition of the population: the Dolgans, Evenks and Yakuts are the indigenous ethnic groups. Adaptation to the harsh local conditions and interaction of different cultures and languages have formed an ethnocultural identity of the inhabitants of this area.

Anabar ulus (district) of Yakutia is a territory with a unique experience of interethnic interaction, economic and cultural adaptive practices. A number of gaps in the historical-geographical and cultural-anthropological studies of the region should be eliminated.

The sources were unpublished materials found in the state and regional archives, current archives of institutions and organizations; the published sources are data of statistical records of the population, reports and information posted on the official websites; field materials collected in Anabar during the expedition in
September 2020, sociological survey and psycholinguistic experiment results.

\section{About Anabar district}

\subsection{Landscape}

Anabar ulus lies beyond the Arctic Circle, in the permafrost zone and tundra landscapes. The harsh climate is softened by the Laptev Sea, which washes the region in the north. The ulus has got its name from the Anabar river that flows into the Anabar Bay. The relief is flat: the region lies on the North Siberian lowland. However, there are ridges of low hills in the northeast and in the south. In the wide valleys of meandering rivers, there are many channels and lakes. There are many lakes in the northern part of the ulus. It borders on Krasnoyarsk Territory, Bulun and Olenek Districts of the Republic of Sakha (Yakutia).

The nature of Anabar is represented by two landscape zones - tundra and forest-tundra. In these conditions, as a result of long historical ties between the Tungus, Yakuts and Russians, the Dolgan nationality formed [2].

\subsection{Population of Anabar District}

Anabar is a place of residence of two ethnic groups: Dolgans and Evenks. Unlike the Tungus-speaking Evenks, the Dolgan ethnos, whose origin is associated with the ancient Evenk clans Dulgan, speaks the language of the Yakut subgroup of the Turkic language family of the Altai language community. The ethnonym 
with the root dol/dul is widespread in the Tungusspeaking environment [3], and the Dolgan language, in addition to the Evenk component, stores "elements of the Yakut language of the period of the first waves of their migration to present-day Yakutia" [4].

The main ethnic settlements are two rural local communities: Saskylakhskoye and YuryungKhainskoye. These communities are characterized by intra-district identification as Evenks (Saskylakh village) and Dolgans (Yuryung-Khaya village).

In 2020, the number of residents in Saskylakh was 2,420 people, in Yuryung-Khaya - 1,216 people. The share of the Saskylakh people is dominated by the indigenous small-numbered peoples of the North 69.3\%. Their distribution is as follows: Evenks - 30.9\%, Dolgans - 27.7\%, Evens - 10.3\%, Yukaghirs - 0.4\%. The share of Yakuts is $25 \%$. In the ethnic structure of Yuryung-Khaya Dolgans are dominant $(74.2 \%)$; the share of Yakuts is $19.7 \%$, the share of Tungus-speaking representatives (Evenks and Evens) is only $2.5 \%$.

The population is polyethnic, which gives particular interest to the study of ethnocultural identification.

\subsection{Traditional Economic Activities}

Deep connections of the traditional nature management of the indigenous peoples of the North with the geographical landscape are one of the most important areas of research in Russian science. Undoubtedly, along with the gradual disappearance of traditional nature management, the accumulated historical experience of ecological culture goes away, as a result, the social structures that form the traditional society disintegrate.

Tundra deer breeding, fishing and hunting have been natural economic activities for the natural conditions of this Arctic territory. In the district, deer are used as a means of transportation for migrations, hunting furbearing animals, fishing. In summer, they collected wild plants (dove and cloudberry), bird eggs, killed wild geese and ducks, and in winter they killed partridges [5].

The main direction of the traditional economy of the indigenous population of Anabar is domestic reindeer herding, which plays a leading role in the socioeconomic development of the region. As of 2019, the total number of deer was 18,050. Today, the reindeer herding companies are Arktika and MUE n.a. Hero Spiridonov, nomadic tribal communities Bolshoy Begichev, Sedeme and Balyksyt. In the ulus, three farms have fishing plots: the Uele tribal community, the N. Ye. Androsov MMUP and A. Koryakin who is an individual entrepreneur; all 14 farms of the ulus are engaged in hunting: 3 municipal enterprises, 5 nomadic tribal communities and 4 individual entrepreneurs in agriculture [6].

In general, the indigenous population managed to preserve and continue to develop the traditional sectors of the economy and land management, with the exception of the Arctic fox fishery. Today, the local population has managed to preserve reindeer pastures (about $72.7 \%$ are used) and hunting grounds distributed among the farms. Additional protection for traditional occupations is the registration of the territory of the Anabar ulus as a territory of traditional nature management and the presence of specially protected natural areas [7].

\section{Indicators of Ethnocultural Identity of Anabar District}

Ethno-cultural identity is the awareness of one's belonging to a particular ethnic community based on the common territory of residence, stable features of culture and language. Thus, there are three main criteria for ethnocultural identity: territorial, cultural and linguistic. Modern culture is characterized by differences between ethnic groups which causes an identity crisis, and the process of preservation is observed ; the growth of ethnic self-awareness caused by social transformations is the basis for ethnocultural identity development [8].

There are many areas that address the issues of ethnic identification based on various methodologies.

Based on the interviews of Anabar residents, the sociological survey and the psycholinguistic experiment, we identified the following criteria of ethnocultural identity.

\subsection{Territorial Identity}

N.A. Mamontova said that earlier the name of a genus group was used to reveal the approximate circle of social connections of the interlocutor. In order to indicate this ability of the Evenks, the author uses the concept of geographical model [9].

During the interviews, many residents pointed to their family and ancestral affiliation. Based on the interviews and published sources, it was established that the Saskylakhs and Yuryung-Khains are descendants of the following clans: Khangalas, Khatygyn, Omoldon, Beti, peasants, Dulgan, Baraakh, Sedeme, Aryyaat, etc. Many ethnonyms are used in the place names of Anabar ulus. The residents distinguish by surnames belonging to a particular genus. For example, the Vinokurovs are the Khangalas, the Androsovs are the Khatygyns, the Tuprins belong to the Sedeme clan, etc. The territorialclan self-identification was studied by local researchers, which indicates the importance of this type of selfidentification.

Settlement is the most important aspect of sociocultural self-identification. The results of the study indicate the division of the inhabitants by the settlements of the ulus: Saskylakhs and Yuryung-Khains. The oldtimers mentioned that earlier the clothes helped to determine where a person is from: "We used to wear shoes with a straight seam (pattern) - lapaika, the Saskylakh people called us "lapayki". Similar markers like clothing or a dialects denote the ethnocultural identity of local groups [10]. In the ulus we did not reveal the division into residents of the periphery and the center, which may be due to their "equivalent" functions: Saskylakh is the regional center; in Yuryung-Khaya, there is a river port that supports the entire ulus. 
However, the population of the ulus, like the majority of the population of the northern regions of Yakutia, emphasize their extreme northern geographical position in relation to the inhabitants of the central part "I will reach diono". The isolation of the region is perceived as a matter of course, reflecting the area of settlement of the Dolgans in this area and nowhere else. This was also reflected in the respondents' answers; only $10.4 \%$ indicated the importance of history and territory in determining nationality.

The general regional self-identification of "Anabars" is characteristic both of the indigenous inhabitants and of those who do not consider themselves either Saskylakh or Yuryung-khain. One of the regional types of selfidentification is the Arctic identity due to a close connection with nature, perception of the Arctic as a homeland.

\subsection{Reindeer herding and hunting culture}

Ethnocultural identification is associated with the traditional economy of the indigenous peoples; the leading occupation has been domestic reindeer herding. In this regard, we observe the persisting figurative and real "reindeer world" of the Anabarians.

Economic and everyday culture is similar to the one of Tungus nomads. In the vocabulary, there are traces of the presence of hunting, fishing and reindeer breeding culture and the absence of cattle breeding culture typical of the Turkic-speaking peoples. When analyzing the reindeer-breeding vocabulary of the Anabar Dolgans, it was revealed that $35.7 \%$ of reindeer-breeding terms are Evenk in origin. The reindeer herding vocabulary is developed, which confirms the fact that reindeer husbandry remains the main economic activity and occupies a significant place in the Dolgan culture. The analysis of vocabulary revealed the predominance of words associated with the names of deer, sex and age characteristics of these animals (27.9\%), their common names $(14.5 \%)$ and habits $(13.1 \%)$. The share of other words related to reindeer husbandry is insignificant and ranges from $4 \%$ to $9 \%$ : the names of deer diseases (4.9\%), games and competitions related to reindeer husbandry $(4.9 \%)$, reindeer in pack-riding and narten transport $(6.5 \%)$, reindeer pastures and forage $(8.2 \%)$, names of deer by the shape of the antlers $(9.8 \%)$ and names of the deer by their external characteristics $(9.8 \%)$.

The results of the free associative experiment conducted in Anabar ulus in 2020 confirmed these assumptions. 150 people of various nationalities took part in the survey. The questionnaires were developed in the Yakut language. Consider the images of cow and horse, which reflect the pastoral culture and the deer image related to the reindeer herding culture.

The image of cow is associated with an animal producing milk similar to a horse which lives in the central mainland. The image of horse is associated with a strong animal, cattle similar to the cow. Such similar reactions indicate that the Anabarians are familiar with these concepts, but they are not the realities of their everyday life.

The image of deer is diverse and can be seen especially clearly in the answers given by the respondents from Yuryung Haya, where the reindeer culture is dominant. For example, the sacred white deer, which is distinguished by its beauty and purity, is a traditional food. Some words from the reindeer herding terminology - deer road or a deer footprint, new sledges, nets, lasso. A single response - reindeer-riding - was given to the "star" stimulus, which suggests some kind of individual experience related to night travel.

Thus, reactions to the image of the deer are present in different areas of life, which indicates the presence of this concept in the life of the Anabarians.

\subsection{Language as a Cultural Indicator}

Ethnocultural identity is based on language, culture, and historical past - these are the unifying features that create a unique image of an ethnic group. A sociological study conducted in Anabar ulus in October-November 2020, in which 201 respondents from Saskylakh and Yuryung-Khaya took part, revealed that the primary marker of ethnic identity is a traditional culture. To the question, "What determines your nationality?" the respondents' answers were distributed as follows: culture and traditions $-60.2 \%$, native language $-26.9 \%$, history and territory $-10.4 \%$.

Based on the sociological research data, we can say that in Anabar, the role of culture and traditions in the process of ethnic identity is the most important ethnic identification criterion. The survey results proved this: 96.7\% of Evenks, $71.8 \%$ of Dolgans, and $92.3 \%$ of Evenks indicated Yakut as their native language, which is $83.1 \%$ of all respondents. The respondents indicated two and sometimes even three languages as their native languages. The majority of respondents also named Yakut as the language of family communication $(94.5 \%)$. The Yakut language is most often used in the forest (taiga) $(50.3 \%)$, in their own locality $(69.7 \%)$, in the district center (54.2\%), and in Yakutsk (49.8\%). However, this fact does not affect the ethnic identity of the peoples inhabiting this area: $51.2 \%$ of Dolgans, $23.4 \%$ of Sakha, $14.9 \%$ of Evenks. $6.5 \%$ of Evenks indicated their own nationality.

According to the results of the sociological survey conducted in Anabar, more than half $(53.2 \%)$ of the respondents said that they observe the traditional rites and customs in everyday life; $26.9 \%$ chose the option "sometimes," and $10.9 \%$ do not observe them. Traditional festive ceremonies are held mainly in Yakut (79.6\%), Russian (35.3\%), Dolgan (34.3\%), and Evenki $(17.9 \%)$ languages, and the option of holding events in a mixed language is also common (22.9\%). The most preserved elements of traditional culture include national food $(70.1 \%)$, everyday clothing $(57.2 \%)$, tools, hunting gear $(45.8 \%)$, and transport $(16.4 \%)$.

Thus, based on the sociological data and analysis of the current research, we can say that a decline in the importance of linguistic identity and traditional culture 
(consisting of ritual practices, national holidays, traditional food culture, and national clothes) remains one of the core components of the ethnic and cultural identity of Arctic peoples as a special kind of metaethnoregional identity character. The uniqueness of the traditional cultures of the Arctic peoples of the North reveals the diversity of local cultures (Dolgan, Evenki, Even, Yakut, Russian) that have emerged on the geo and ecocultural landscape of the Khatango-Anabar region. This represents a single environment of ethnic groups in the context of interethnic and intercultural relations, which will be the subject of further research of ethnosocial and cultural processes in this region.

\section{Conclusion}

Thus, the ethnocultural identity of residents of Anabar is determined by three criteria:

- territorial, containing family and clan historical memory of the region of residence and including the settlement affiliation of the inhabitants of two municipalities - Saskylakh and Yuryung-Khaya and positioning as a regional community - "Anabarians" and "residents of the Arctic";

- linguistic, not dominant for ethnic identification, when the language of communication for the majority of the indigenous population (Dolgans, Evenks, Yakuts, Evens, etc.) is Yakut; native languages are taught at school (Dolgan and Evenki), and the official language is Russian;

- cultural, fueled by Arctic traditional activities and their sustainability, elements of the traditional way.

\section{Acknowledgment}

The article was carried out within the framework of the grant "Khatango-Anabar region in the XX-early XXI centuries: anthropology of the cultural landscape" of the Russian Foundation for Basic Research, grant No. 2009-00257A

\section{References}

1. V. A. Tishkov, Herald of the Russian Academy of Sciences. $\quad \mathbf{8 9 ( 4 )} 408-412 \quad$ (2019). $\quad$ DOI: https://doi.org/10.1134/S1019331619020229

2. V. I. D'yachenko, Hunters of high latitudes. Dolgans and northern Yakuts (2005) [In Russian].

3. G. M. Vasilevich, Sovetskaya ethnografiya 4 34-49 (1946) [In Russian].

4. N. M. Artemyev, Dolgan language: structural and semantic analysis. PhD abstract, (2001) [In Russian].

5. Anabar District: A history. Culture. Folklore (2005) [In Russian].

6. Municipal program "Development of agriculture and food of Anabar District for 2020-2024» (2019) [In Russian].

7. V. V. Filippova, L. I. Vinokurova, Ya. M. Sannikova, N. E. Zakharova, A. E. Mestnikova, Nauchnyi dialog, 11, 495-508(2020). DOI: 10.24224/22271295-2020-11-495-508 [In Russian].

8. N. R. Krasovskaya. The Authority, 4 (2020) DOI: https://doi.org/10.31171/vlast.v28i3.731 [In Russian].

9. N. A. Mamontova. Identity and language of the IlympicEvenks in the XX-XXI centuries. PhD abstract, Moscow (2013) [In Russian].

10. N. I. Shietova, Tomsk journal of linguistics and anthropology, 2, 160-170 (2020). 